\section{New GLORIA in record time}

GLORIA III, the latest model of the British deep-sea side-scanning sonar which has fired the imagination of geologists worldwide, has been built in record time at the Institute of Oceanographic Sciences (IOS) at Wormley, Surrey for the US Geological Survey (USGS) and is due to undergo trials off the continental shelf later this week. If all goes well, the converted trawler Farnella will set sail with the new GLORIA for the icy waters of the Bering Sea, where GLORIA's sonar beams will be trained onto the sea floor of the United States' northernmost Exclusive Economic Zone (EEZ). Meanwhile, yet another GLORIA is on the drawing boards, but this time to be built by private enterprise.

The new GLORIA's predecessors, I and II, have already mapped more than 2 per cent of the world's ocean floor, including EEZs off the US west coast, Puerto Rico, the Virgin Islands, and in the Gulf of Mexico, revealing many geological features including sinuous deep-sea canyons, hundreds of previously unknown submarine volcanoes, faults, submarine slides, metal-rich deposits and manganese nodule fields. Results from the US west coast were published earlier this month in a huge atlas of glossy black and white sonograph mosaics by USGS using stateof-the-art image-processing techniques.

GLORIA, short for Geological LongRange Inclined ASDIC, is a torpedo-like "towfish" that scans the sea floor with two sonar beams that "illuminate" the sea bed in a swathe up to $30 \mathrm{~km}$ wide on either side of the ship track. Two rows of 30 transducers on either side of the towfish emit a 4-second FM "chirp" within the range 6.2 to $6.8 \mathrm{kHz}$; frequency modulation of the signal allows recognition of the return echo even if the chirp has been half swallowed by the sea floor. The time of return of echoes and their strength are digitally recorded and printed out as sonographs which resemble an oblique aerial photograph but with an important difference. Whereas aerial photographs resolve different objects by registering angular variations, sonar resolves them by measuring differences of slant range. Thus the interpretation of sonographs can be equivocal, but ambiguities are largely resolved by overlapping the swathes to obtain a view of any feature from both sides and by using bathymetric maps to pin down the source of echoes. The sonographs not only reveal local topography but can also indicate the nature of the bottom - sandy beds and manganese nodule fields show up as bright spots because they resound like a bell when hit by GLORIA's sound waves.

Improvements in the Mark

III

GLORIA include titanium transducers and a digitized beam-steering unit to correct for yaw, while a new laser printer will be used to produce high-quality sonographs at sea, but these changes are minor compared to the giant stride forward made between Marks I and II. Mark I was a cumbersome 6-tonne Goliath $10 \mathrm{~m}$ in length and nearly $2 \mathrm{~m}$ in diameter that had to be manhandled by a team of eight, including divers. Surveys were thus confined to sheltered waters such as the Mediterranean, and GLORIA I could be operated only from RSS Discovery which had the necessary permanent installations. By contrast, Mark II, a slim featherweight at 2 tonnes and $0.6 \mathrm{~m}$ diameter, can be deployed from many ships and has successfully been recovered in two hurricanes, including its namesake hurricane Gloria in the Gulf of Mexico. But demand for GLORIA II's services has simply proved too great, and agreement was made to construct a twin for USGS with US funds (see Nature 312, 688; 1984). Although the first components for GLORIA III were purchased about a year ago, work on the new model did not get into full swing until December, when the GLORIA team returned from sea, and from late January IOS scientists worked into the night to complete GLORIA on schedule.

After testing GLORIA at "full-beam" off the continental slope, Farnella will return to Falmouth on 18 April before heading for San Francisco through the Panama Canal. The survey of the Bering Sea is scheduled to begin in late June and run to

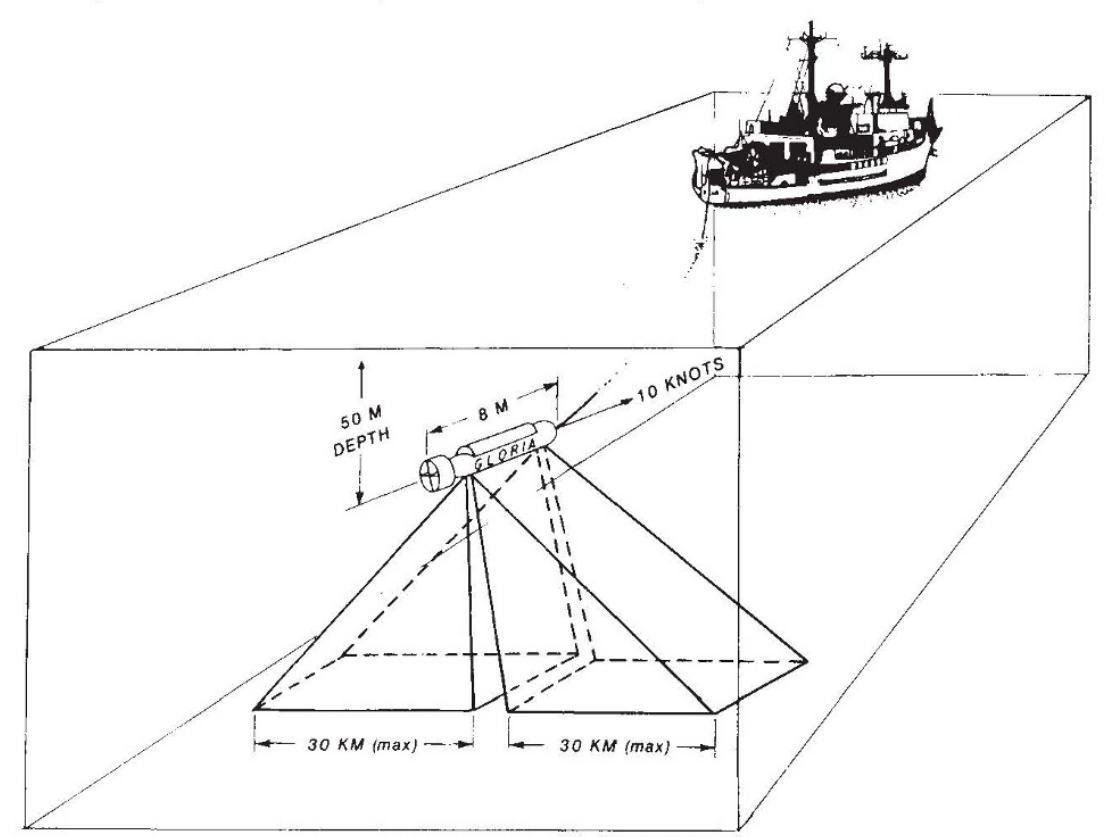

GLORIA is neutrally buoyant and is towed about $300 \mathrm{~m}$ behind the mother ship. On "full beam" at a water depth of $5,000 \mathrm{~m}$, GLORIA scans a swath of sea floor about $60 \mathrm{~km}$ wide and the time interval between sonar pulses is set at 40 seconds to allow time for the most distant echoes to return; at shallower depths, the area covered and the time between pulses are reduced.

the end of September, after which attention will turn to the EEZ around Hawaii. Beyond that, the sea floor around Guam is a future target for insonification, as is the east coast of the United States, but it is unlikely that the two existing GLORIAs (II and III) can cope with the ever-increasing demand for their services, which is where private enterprise may step in.

Marconi have signed an exclusive licensing agreement with the Natural Environment Research Council to produce yet more GLORIAs. Alastair Johnson, director of Marconi's newly-formed Maritime Applied Research Laboratory, sees enormous potential in the Pacific, where several island nations with large EEZs have expressed interest in GLORIA. 